\title{
Efeito do crédito do BNDES para a geração de empregos agroindustriais no Brasil ${ }^{1}$
}

\section{Effect of BNDES credit on agroindustrial employment generation in Brazil}

\author{
Jackelline Favro' ${ }^{1}$, Alexandre Florindo Alves $2,3 *$ (D) \\ 1Programa de Pós-graduação em Ciências Econômicas, Universidade Estadual de Maringá (UEM), Maringá (PR), Brasil. E-mail: \\ jacke.favro@gmail.com \\ 2Departamento de Ciências Econômicas, Programa de Pós-graduação em Ciências Econômicas, Universidade Estadual de Maringá \\ (UEM), Maringá (PR), Brasil. E-mail: afalves@uem.br \\ 3Programa de Pós-graduação em Agroecologia - Mestrado Profissional, Universidade Estadual de Maringá (UEM), Maringá (PR), \\ Brasil.
}

\begin{abstract}
Como citar: Favro, J., \& Alves, A. F. (2022). Efeito do crédito do BNDES para a geração de empregos agroindustriais no Brasil. Revista de Economia e Sociologia Rural, 60(4), e229587. https://doi.org/https://doi.org/10.1590/18069479.2021 .229587
\end{abstract}

Resumo: No Brasil, o crédito público tem papel relevante no apoio às empresas, em especial àquelas pertencentes ao setor industrial. Nesse sentido, este estudo tem por objetivo realizar uma avaliação do impacto dos desembolsos do Banco Nacional de Desenvolvimento Econômico e Social (BNDES) na geração de empregos na agroindústria brasileira. Para tanto, utilizaram-se microdados da Relação Anual de Informações Sociais (RAIS) e do BNDES no âmbito empresarial. As técnicas econométricas empregadas foram Propensity Score Matching (PSM) e Diferenças em Diferenças (DID). Foram tomados como referência os períodos pré e pós-expansão dos desembolsos do BNDES, em virtude da política anticíclica adotada pelo governo em 2009, para conter os impactos da crise internacional deflagrada em 2008. Os resultados encontrados apontam que, para a amostra em análise, empresas financiadas entre 2009 e 2010, o impacto no crescimento do emprego foi estatisticamente significativo e as empresas que receberam crédito do BNDES apresentaram dinâmica diferenciada em termos de geração de emprego. Tais resultados evidenciam que a ampliação da política de desembolsos do BNDES consistiu em um instrumento importante sobre a geração de emprego em empresas pertencentes à agroindústria.

Palavras-chave: avaliação de impacto, Banco Nacional de Desenvolvimento Econômico e Social, Agroindústria.

\begin{abstract}
In Brazil, public credit plays an important role in supporting companies, especially those belonging to the industrial sector. In this regard, this study aims at carrying out an assessment of the impact of disbursements by Brazilian Development Bank (BNDES) on job creation in Brazilian agroindustry. For this purpose, the microdata of the Annual Listing of Employees and Salaries (RAIS) and the BNDES were used at the company scope. The econometrics techniques used were the Propensity Score Matching (PSM) and Differences-in-Differences (DID). The period before and after expansion of BNDES disbursements was taken as a reference, due to the countercyclical policy adopted by the government in 2009 to contain the impacts of the international crisis triggered in 2008. The results found indicate that, for the sample under analysis, companies financed between 2009 and 2010, the impact on employment growth was statistically significant and revealed that the companies that received credit from BNDES had different dynamics in terms of job creation. These results show that the expansion of the BNDES disbursement policy was an important instrument on job creation in companies belonging to the agroindustry.
\end{abstract}

Keywords: impact assessment, The Brazilian Development Bank, Agroindustry.

${ }^{1}$ O presente trabalho foi realizado com o apoio da Coordenação de Aperfeiçoamento de Pessoal de Nível Superior Brasil (Capes) - Código de Financiamento 001.

* O autor ALVES, A.F. é bolsista como Tutor do PET Economia da UEM. 


\section{Introdução}

As perspectivas de crescimento contínuo da demanda por alimentos e produtos agrícolas constituem um incentivo ao desenvolvimento da agroindústria² ${ }^{2}$ que consiste em um componente do setor manufatureiro, em que é adicionado valor às matérias-primas agropecuárias por meio de operações de processamento e manuseio. Esse segmento da indústria é considerado eficiente motor de crescimento e desenvolvimento, principalmente em países em desenvolvimento, como é o caso do Brasil, pois estes têm potencial para gerar emprego e renda para a população rural e a urbana (Shepherd et al., 2009).

Diante dessa realidade, constata-se a importância de se desenvolver atividades agroindustriais. Nesse sentido, as políticas públicas de liberação de crédito para atividades industriais apresentam papel importante nesse processo, pois podem servir como mecanismos de dinamização da economia local e contribuir para a eficiência e o desenvolvimento dos segmentos que compõem a agroindústria, ocasionando, assim, geração de emprego e renda em regiões onde essas indústrias estão instaladas, contribuindo para a redução das disparidades regionais e o desenvolvimento regional.

Em relação às políticas de crédito que contribuem para o desenvolvimento da agroindústria, verifica-se que o Banco Nacional de Desenvolvimento Econômico e Social (BNDES) provê o financiamento de longo prazo para todos os segmentos da economia brasileira. O banco tem por objetivo promover a competitividade da economia ao investir em áreas como pesquisa e desenvolvimento, infraestrutura, promoção de exportações, desenvolvimentos regional e urbano, entre outras iniciativas. No setor industrial, o BNDES financia projetos de longo prazo para criação de novas plantas, ampliação de plantas existentes, restruturação e modernização de processos produtivos, inovação e desenvolvimento tecnológico (Sousa \& Ottaviano, 2018).

A atuação do BNDES na economia brasileira é de significativa importância, principalmente desde a década de 2000, período em que o banco se destacou por promover o financiamento de longo prazo com aumento expressivo dos desembolsos para todos os segmentos produtivos, inclusive para a agroindústria (Bel Filho et al., 2012).

No que concerne ao financiamento à agroindústria, ao longo dos últimos anos, o banco vem apresentando crescimento no financiamento a este segmento produtivo. De acordo com os dados do BNDES (Banco Nacional de Desenvolvimento Econômico, 2015), referentes ao período de 2000 a 2014, os desembolsos totais do BNDES à agroindústria aumentaram, em termos reais, $156 \%$ (de $R \$ 9,4$ bilhões para quase $R \$ 24,1$ bilhões). Nesse período, destacou-se o ano de 2010, em que os desembolsos chegaram aos maiores níveis registrados para este segmento até então. Esse fato ocorreu em virtude da política de crédito, implementada na economia brasileira em 2009, que consistiu em uma das medidas da política anticíclica ${ }^{3}$ adotada pelo governo para conter os impactos da crise internacional deflagrada em 2008.

Dado o exposto, questiona-se: mediante o boom de financiamentos associado à política anticíclica, os desembolsos do BNDES para a agroindústria no período de 2009 a 2010 foram efetivos para o crescimento desse segmento em termos de geração de emprego?

\footnotetext{
2 Compreende-se como agroindústria toda atividade de beneficiamento e/ou transformação de matérias-primas derivadas de produtos agrícolas, pecuários, pesqueiros, aquícolas, extrativistas, de processos mais simples (secagem, classificação, limpeza e embalagem) aos mais complexos (operações físicas, químicas ou biológicas, como extração de óleos, caramelização e fermentação), incluindo também o artesanato no meio rural (Brasil, 2007).

${ }^{3}$ A literatura define políticas anticíclicas como aquelas que revertem situações recessivas de crises ou depressões. Em países em desenvolvimento, como o Brasil, os bancos públicos assumem papel importante na execução dessas políticas, cuja intervenção tem finalidade de suavizar os cíclicos da atividade econômica (Simonassi et al., 2017). Os bancos públicos anticíclicos, em oposição à volatilidade e às incertezas presentes no mercado privado, têm papel vital para aumentar a oferta de crédito, num cenário de restrição e aumento do custo dos empréstimos, exercendo a função de mitigar os efeitos recessivos (Oliveira, 2016a).
} 
Com base no problema central, o objetivo geral deste estudo consiste em investigar o efeito da oferta de crédito do BNDES sobre o crescimento do emprego formal de empresas agroindustriais brasileiras para o período de 2008 a 2010, pelo fato de captar as mudanças em termos de liberação de crédito e efeitos desses financiamentos no período pré e na pósimplementação da política anticíclica.

Para tanto, utilizaram-se os dados da Relação Anual de Informações Sociais (RAIS) identificada que possibilita isolar os efeitos do impacto no emprego em empresas que receberam o crédito do BNDES no período em análise. Para obter o efeito médio de tratamento da política sobre as empresas da agroindústria que receberam financiamento no período, duas técnicas foram utilizadas: o Pareamento por Escore de Propensão (Propensity Score Matching [PSM]) e o método de Diferenças em Diferenças (DID). O primeiro possibilitou a construção de um grupo de controle adequado e o segundo foi empregado para comparar os resultados do grupo de tratamento e de controle antes (2008) e depois da intervenção (2009 e 2010).

Esse estudo se justifica, pois, apesar da atuação expressiva do BNDES nesse período, contribuindo com mais liberação de crédito, as análises sobre a avaliação dos impactos gerados por essa política na economia e, em particular, na agroindústria ainda são pouco exploradas.

O presente trabalho está organizado da seguinte forma: além desta introdução, possui mais seis seções. Na segunda seção, realiza-se uma análise sobre o panorama dos desembolsos do BNDES para a agroindústria. Na terceira seção, aborda-se o referencial teórico e empírico e a quarta apresenta a metodologia e a base de dados. Na quinta, expõem-se os resultados do estudo e, na sexta seção, as considerações finais.

\section{Panorama dos desembolsos do BNDES para o conceito amplo de agroindústria}

Considerando-se o conceito amplo de agroindústria ${ }^{4}$, a Figura 1 apresenta o valor dos desembolsos do BNDES e o número de operações durante o período de 2002 a 2014. Podese constatar que, a partir de 2004, os valores destinados à agroindústria em sentido amplo apresentaram crescimento, o qual se manteve até 2008. Em 2009, os desembolsos do BNDES sofreram queda (entre os fatores, pode-se destacar a crise econômica internacional que ocorreu no segundo semestre de 2008) e, a partir de 2010, pode-se verificar notória mudança com o crescimento exponencial dos desembolsos ${ }^{5}$. De acordo com Simonassi et al. (2017), esse fato

\footnotetext{
${ }^{4}$ De acordo com Favro (2019), as subclasses de atividades da CNAE (versão 2.0) referentes à indústria de transformação que fazem parte do conceito de agroindústria são: todas as subclasses pertencentes à indústria de alimentos, bebidas e fumo. Fabricação de produtos têxteis são consideradas as subclasses:1311-1/00; 1312-0/00; 1321-9/00; 1322-7/00. Confecção de artigos do vestuário e acessórios são consideradas as subclasses:1412-6/02; 1414-2/00; preparação de couros e fabricação de artefatos de couro são consideradas as subclasses:1510-6/00; 1529-7/00; 1531-9/01; fabricação de produtos de madeira são consideradas as subclasses: 1610-2/01; 1610-2/02; 1621-8/00; 1622-6/01; 1622-6/02; 1622-6/99; 1623-4/00; 1629-3/02; 1629-3/01; fabricação de celulose, papel e produtos de papel são consideradas as subclasses: 1710-9/00; 1721-4/00; 1722-2/00; 1731-1/00; 1732-0/00; 1733-8/00; 1741-9/01; 1741-9/02; 1742-7/99; fabricação de coque, de produtos derivados do petróleo e de biocombustíveis são consideradas as subclasses:19314/00 ; 1932-2/00; fabricação de móveis é considerada a subclasse:3101-2/00.

5 Em razão da crise internacional (desencadeada pelo mercado subprime dos Estados Unidos) instaurada em 2008 , diversos setores industriais tiveram forte desaceleração nas vendas de seus produtos. Para corrigir e atenuar o problema, 0 governo federal adotou um conjunto de medidas anticíclicas que, em essência, tinham por objetivo estimular o setor privado nacional a reverter as expectativas pessimistas quanto ao funcionamento futuro da economia (Araújo \& Pires, 2010).

Araújo \& Gentil (2011) ressaltam que as medidas abrangiam, em geral, desonerações fiscais, manutenção do gasto público, redução no compulsório, expansão do crédito pelos principais bancos públicos e redução da taxa básica de juros. No que diz respeito ao BNDES, houve ampliação das linhas de financiamento às exportações e ao capital de giro e o banco foi responsável por cerca de um terço da expansão do crédito no país, contribuindo para a manutenção do nível de emprego e renda (Couto \& Trintim, 2012).
} 
evidencia a decisiva atuação do BNDES em 2009 por meio da política anticíclica ${ }^{6}$ para reverter o iminente cenário de recessão na economia brasileira.

A partir de 2013, observa-se queda dos desembolsos do BNDES para a agroindústria, entretanto, apesar do declínio no valor dos desembolsos, pode-se verificar que o número de contratos ainda permaneceu elevado.

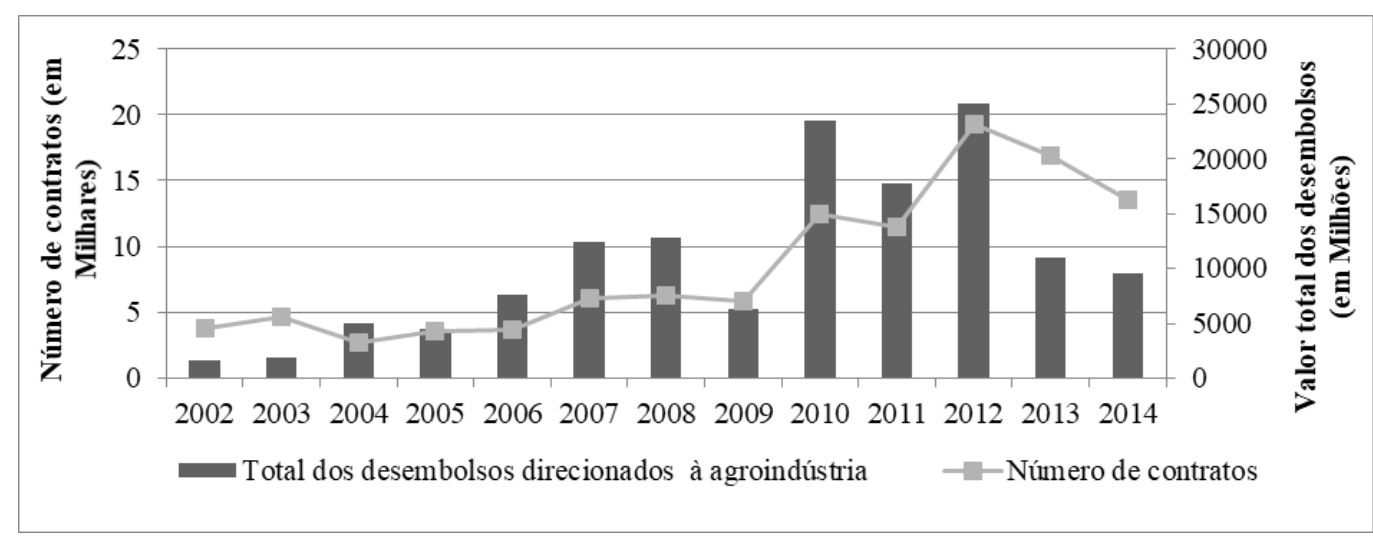

Figura 1. Valor e número de operações dos desembolsos do BNDES para a agroindústria no período de 2002 a 2014. Fonte: elaboração própria com dados do BNDES (Banco Nacional de Desenvolvimento Econômico, 2017b).

Ao se analisar a participação relativa do número de contratos por subsetor da indústria, verifica-se que a produção de alimentos representou mais de $50 \%$ do número de contratos de crédito para a agroindústria no período de 2002 a 2014 (Figura 2).

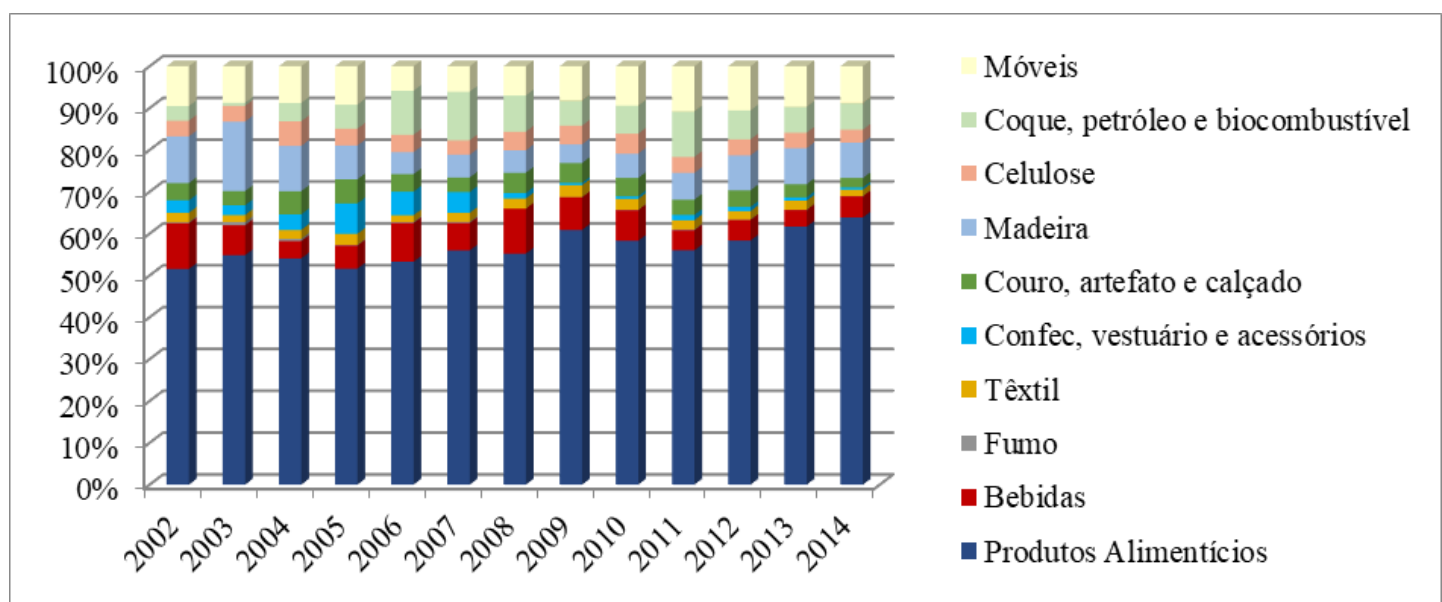

Figura 2. Participação relativa do número de contratos dos desembolsos do BNDES voltados à agroindústria por subsetor da indústria de transformação no período de 2002 a 2014. Fonte: elaboração própria com dados do BNDES (Banco Nacional de Desenvolvimento Econômico, 2017b).

\footnotetext{
${ }^{6}$ Nesse período, o BNDES foi utilizado como um instrumento de política anticíclica. Empréstimos realizados pela Secretaria do Tesouro Nacional (STN) ao banco de fomento alavancaram sua capacidade de emprestar para as empresas e levaram a que o crédito direcionado à pessoa jurídica crescesse expressivamente entre 2009 e 2010. Os desembolsos do BNDES cresceram de 1,6 p.p. do PIB, em dezembro de 2008, para 3,5 p.p. do PIB, em dezembro de 2010. Desse modo, a atuação do BNDES levou a que o crescimento do crédito direcionado à pessoa jurídica, de 2,7 p.p. do PIB, entre 2008 e 2010, mais que compensasse a retração do crédito com recursos livres, de 1,0 p.p. do PIB (Mora, 2015).
} 
No que concerne ao valor dos desembolsos por subsetores (Figura 3), pode-se destacar a importante participação da produção de alimentos como segmento que mais recebeu investimentos do BNDES. Outros dois segmentos se destacaram no período em análise, o de celulose e coque, petróleo e biocombustível. O subsetor da celulose teve participação significativa nos desembolsos do BNDES em 2004 e 2006. De acordo com o BNDES (Banco Nacional de Desenvolvimento Econômico, 2007), esse fato pode ser justificado em virtude das expectativas positivas para esse segmento, ocasionadas pelo volume crescente de exportações e pelo aumento da demanda interna.

Já no que se refere aos desembolsos ao subsetor de coque, petróleo e biocombustível que, na agroindústria, compreende a produção de álcool e biocombustíveis, pode-se verificar expressiva participação a esse segmento a partir de 2007. Entre as justificativas para essa maior participação, está o aumento da demanda por etanol ocasionada, entre outros fatores, pela maior produção de veículos flex-fuel. De acordo com Kohlhepp (2010), a partir de 2003 veículos com motor flex-fue/ começaram a ser produzidos em série no Brasil. Em março de 2004, 16\% dos veículos novos vendidos no Brasil já eram equipados com esse tipo de motor. Em fevereiro de 2006 , havia $76,6 \%$, em novembro de $2007,86,1 \%$ e, em 2010 , mais de $92 \%$. O aumento da produção de veículos com essa tecnologia ocasionou o crescimento da demanda por etanol, o que pode ter contribuído para que empresas desse segmento realizassem financiamentos com o BNDES para efetivar projetos de expansão da estrutura industrial com o objetivo de aumentar a produção de etanol para atender à demanda crescente.

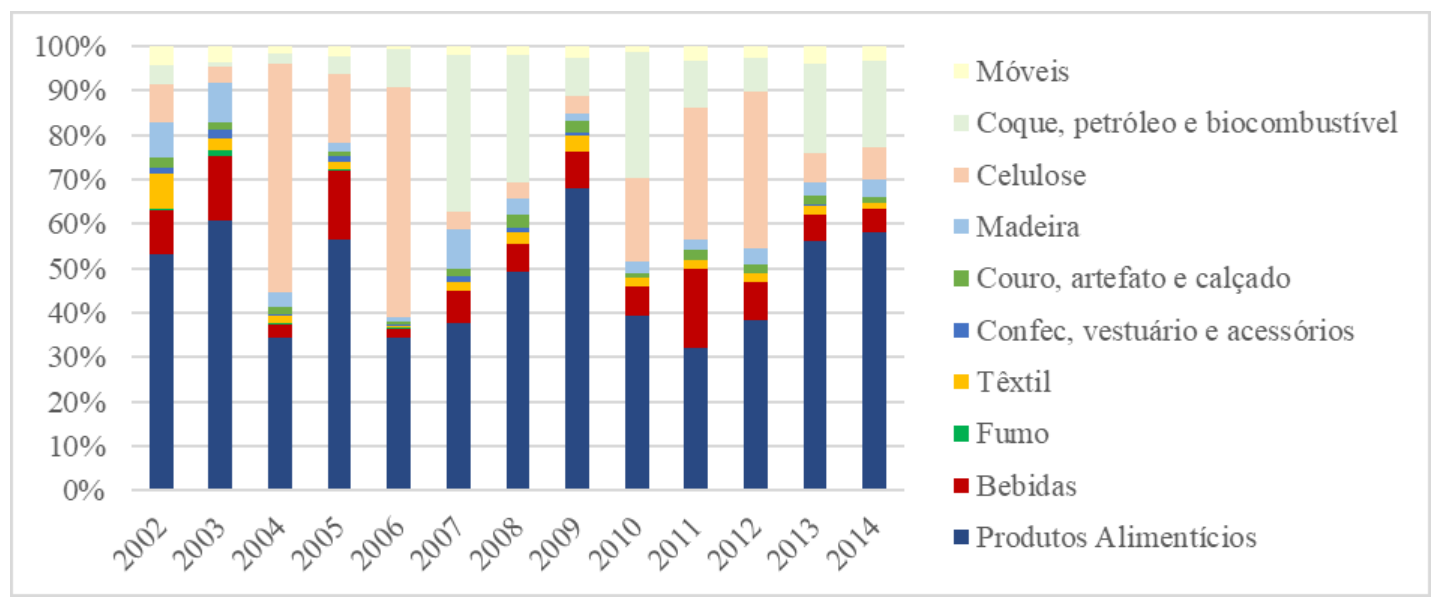

Figura 3. Participação relativa do valor dos desembolsos do BNDES por subsetores da indústria de 2002 a 2014. Fonte: elaboração própria com dados do BNDES (Banco Nacional de Desenvolvimento Econômico, 2017b).

Apesar de os dados referentes ao total de contratos e ao valor dos desembolsos constatarem o crescente apoio do BNDES ao financiamento à agroindústria, é relevante analisar se esse fato também se verifica quando se observam os dados referentes às regiões, pois, por meio de uma análise desagregada em âmbito regional, é possível observar, em termos espaciais, a localização dos desembolsos do BNDES e seu grau de importância entre as regiões.

No que concerne ao número de contratos em termos regionais (conforme apontado na Tabela 1), verifica-se que os desembolsos do banco para a agroindústria, no período de 2002 a 2011, foram predominantemente para empresas sediadas nas regiões Sudeste e Sul.

Esse fato se justifica por essas regiões se destacaram por concentrar grande parte da produção agroindustrial brasileira. Isso pode ser evidenciado em termos de número de estabelecimentos, 
estoque de empregos formais e pela participação dessas regiões no Valor da Transformação Industrial da Agroindústria ${ }^{7}$. No que concerne ao número de estabelecimentos, os dados da RAIS (Relação Anual de Informações Sociais, 2020) apontam que, no período de 2007 a 2011, aproximadamente $71 \%$ dos estabelecimentos pertencentes à agroindústria estavam concentrados nessas regiões, estando $37 \%$ dos estabelecimentos localizados na região Sudeste e 34\%, na região Sul do País. Já com relação ao estoque de empregos formais na agroindústria, essas regiões também se destacaram por concentrar aproximadamente $67 \%$ dos empregos desse segmento, sendo $38 \%$ na região Sudeste e $29 \%$ na região Sul.

No que se refere à produção, de acordo com dados do IBGE (Instituto Brasileiro de Geografia e Estatística, 2020), no período de 2007 a 2011, em média, 71\% do VTI da agroindústria brasileira foi proveniente das regiões Sul e Sudeste, sendo $46 \%$ a participação da região Sudeste e $25 \%$ a da região Sul. Todos esses dados demonstram a importância dessas regiões, justificando, assim, a participação expressiva delas no total de contratos do BNDES.

No que concerne às regiões Nordeste, Centro-Oeste e Norte, verifica-se que, apesar de apresentarem crescimento no número de contratos no período em análise, representaram menos participações. Esse fato pode ser justificado em virtude da participação dessas regiões em termos de número de estabelecimentos e estoques de empregos formais na agroindústria. De acordo com os dados da RAIS (Relação Anual de Informações Sociais, 2020), as regiões Norte, Nordeste e Centro-Oeste concentraram, em média, ao longo do período de 2007 a 2011, aproximadamente $5 \%, 15 \%$ e $9 \%$, respectivamente, dos estabelecimentos da agroindústria brasileira. Já com relação ao estoque de empregos formais, a participação conjunta dessas regiões foi de aproximadamente $32 \%$, sendo $4 \%$ na região Norte, $19 \%$ na região Nordeste e $9 \%$ na região Centro-Oeste.

Apesar de as regiões Norte, Nordeste e Centro-Oeste do país não seguirem o mesmo perfil de atração da agroindústria das regiões Sul e Sudeste, ao longo do período de 2007 a 2017, apresentaram expressivas taxas de crescimento da planta agroindustrial, principalmente a região Centro-Oeste. Este fato justifica o crescimento no número de contratos direcionados a esse segmento no período de 2007 a 2011 (Favro, 2019).

Tabela 1. Número de contratos do BNDES para a agroindústria por regiões de 2002 a 2011

\begin{tabular}{ccccccccccc} 
Regióes & $\mathbf{2 0 0 2}$ & $\mathbf{2 0 0 3}$ & $\mathbf{2 0 0 4}$ & $\mathbf{2 0 0 5}$ & $\mathbf{2 0 0 6}$ & $\mathbf{2 0 0 7}$ & $\mathbf{2 0 0 8}$ & $\mathbf{2 0 0 9}$ & $\mathbf{2 0 1 0}$ & $\mathbf{2 0 1 1}$ \\
Sul & 1.396 & 1.596 & 1.128 & 1351 & 1.146 & 2.143 & 2.124 & 2.310 & 4.417 & 4.368 \\
Sudeste & 1.675 & 1.972 & 1.074 & 1641 & 1.882 & 2.742 & 2.867 & 2.629 & 5.187 & 4.621 \\
Centro-Oeste & 197 & 376 & 181 & 182 & 204 & 507 & 638 & 455 & 1.123 & 1.208 \\
Nordeste & 442 & 497 & 207 & 301 & $\mathbf{7 9}$ & 448 & 457 & 348 & 1.244 & 979 \\
Norte & 124 & 245 & 86 & 116 & 315 & 161 & 172 & 127 & 399 & 316 \\
Total & $\mathbf{3 . 8 3 4}$ & $\mathbf{4 . 6 8 6}$ & $\mathbf{2 . 6 7 6}$ & $\mathbf{3 5 9 1}$ & $\mathbf{3 . 6 2 6}$ & $\mathbf{6 . 0 0 1}$ & $\mathbf{6 . 2 5 8}$ & $\mathbf{5 . 8 6 9}$ & $\mathbf{1 2 . 3 7 0}$ & $\mathbf{1 1 . 4 9 2}$ \\
\hline
\end{tabular}

Fonte: elaboração própria com dados do BNDES (Banco Nacional de Desenvolvimento Econômico, 2017b).

Em relação ao total de contratos, verifica-se que, de 2004 e 2005, houve redução no número de contratos direcionados à agroindústria. Esse fato ocorreu em razão de essa cadeia produtiva ter sido prejudicada por diversas crises que afetaram alguns de seus segmentos. Entre eles, destaca-se o setor de carnes que foi afetado pela gripe aviária e pela febre aftosa, que, em

7 O valor da transformação industrial (VTI) é resultado do valor bruto da produção industrial menos o custo das operações da indústria. Consiste em uma proxy do valor adicionado (Instituto Brasileiro de Geografia e Estatística, 2018). 
conjunto com problemas cambiais, representaram desaceleração no crescimento desse segmento. De forma geral, as commodities também sofreram com o câmbio desfavorável e a queda dos preços internacionais nesse período (Jesus Júnior et al., 2007).

Por meio dos dados apresentados, observa-se uma mudança de perfil na liberação de crédito do BNDES a partir de 2007, sendo mais representativa em 2010, ano que se destacou por apresentar o maior número de contratos no total e por exibir crescimento expressivo de contratos entre as regiões. Nesse ano, em virtude da implementação da política anticíclica, houve o aumento da disponibilidade de assistência financeira com o intuito de mitigar os efeitos da crise internacional sobre a economia brasileira. Nesse contexto, o BNDES aumentou seus desembolsos de recursos para os setores produtivos e infraestrutura, impactando, consequentemente, os segmentos da agroindústria de modo geral.

Dado o exposto, pode-se constatar que a maior participação do BNDES no financiamento às empresas da agroindústria, ocorrida, principalmente, em 2010, pode ter contribuído para que esse segmento produtivo pudesse se desenvolver e gerar emprego e renda nesse período marcado por uma profunda crise internacional ${ }^{8}$.

\section{Referencial teórico}

O mercado de crédito contribui para o desenvolvimento econômico, sendo responsável pela captação e distribuição de recursos entre os diversos agentes da economia (Todaro \& Smith, 2012). O desenvolvimento desse mercado contribui para a redução de custos de transação e assimetrias informacionais entre agentes, facilitando o acesso aos recursos financeiros e promovendo o crescimento e o desenvolvimento econômico (Daniel, 2016).

Portanto, o acesso ao crédito se destaca como uma ferramenta importante para o crescimento das empresas e para estimular a inovação tecnológica. A população também se beneficia em virtude de as empresas acessarem o crédito. Esse benefício ocorre por meio dos impactos econômicos causados pela intervenção, via geração de emprego, renda, crescimento e desenvolvimento econômico (Daniel, 2016).

Em contrapartida, a escassez de recursos financeiros nos mercados pode afetar negativamente o crescimento das empresas, especialmente entre as de pequeno porte, pois a restrição de crédito possui influência decisiva para o comportamento e execução dos empreendimentos (Beck et al., 2005).

Para Lee \& Chambers (1986), as restrições de crédito, ao afetar as decisões de produção em âmbito de firma, acabam por impactar o comportamento da produção agregada. Portanto, ao afetar as decisões de alocação das firmas, esta exerce influência sobre os resultados econômicos.

Desse modo, pode-se constatar que a restrição de crédito limita o crescimento das firmas e, consequentemente, restringe o crescimento e o desenvolvimento econômico. Entretanto, na presença de racionamento de crédito, o financiamento público pode contribuir para impulsionar o desempenho das firmas. Esse fato justifica a intervenção do governo com o intuito de reduzir as imperfeições do mercado financeiro, possibilitando mais acesso ao crédito.

O esforço ou a intervenção governamental justifica-se em virtude dos benefícios gerados a partir do acesso ao crédito, pois os empreendimentos tornam-se mais produtivos e eficientes, contribuindo, assim, com o desempenho da economia (Taylor \& Shonkwiler, 1986 apud Daniel, 2016).

8 A crise econômica internacional de 2008-2009 teve efeitos graves, como a contração do crédito em escala internacional, a queda do produto interno bruto (PIB) das economias desenvolvidas e a queda acentuada do comércio internacional, que chegou a US \$27,1 trilhões em 2007 a US \$ 24 trilhões em 2008 (Oliveira, 2016a). 
O principal objetivo dos programas de crédito público consiste em apoiar o aumento da competitividade e geração de emprego em pequenas e médias empresas, canalizando financiamento de médio e longo prazos para investimentos. Fundos e programas são utilizados para financiar investimentos fixos ou de capital de giro permanente associado à execução de projetos de investimento para essas empresas (Maffioli et al., 2016).

A atuação dos bancos de desenvolvimento também contribui para o amadurecimento econômico de um país e é considerada relevante no âmbito das políticas econômicas, pois estas instituições possuem papel específico no investimento nacional não apreciado pelas demais instituições financeiras (Oliveira et al., 2015).

Conforme Bruck (1998) e Yeyati et al. (2004), os bancos estatais de desenvolvimento se especializaram em fornecer capital de longo prazo e empréstimos para empresas que de outra forma não poderiam financiar seus projetos.

Esses bancos representam um dos mecanismos de atuação do Estado no sistema financeiro e podem ser orientados, segundo Hermann (2010), segundo dois aspectos:

- Modelo de Shaw e McKinnon, em que privilegia a atuação mínima do Estado nos setores da economia, tendo-se em vista que, em mercados desenvolvidos, a assimetria de informações é reduzida, razão pela qual a iniciativa privada é capaz de garantir suficiência do mercado. Neste caso, o Estado atua como coadjuvante do mercado financeiro e os bancos de desenvolvimento não teriam nenhuma representatividade.

- Filiação keynesiana, que apoia a ampliação da atuação do Estado na economia com o objetivo de corrigir a assimetria de informações e incertezas inerentes ao mercado. Os mercados financeiros tendem a se expandir de forma incompleta e a atuação do Estado se torna necessária.

O contexto da economia mundial, no início do século XX, evidenciou que o mercado financeiro estritamente privado é incompleto e não alcança segmentos importantes, sobretudo atividades cujo maior atrativo é a rentabilidade social e os investimentos nas pequenas e médias empresas que representam importantes fontes de emprego (Bruck, 1998; Hermann, 2010). Tais demandas justificam a atuação, de caráter complementar, dos bancos de desenvolvimento, como provedores de crédito e promotores do desenvolvimento (Bruck, 1998; Hermann, 2010).

De forma geral, os bancos de desenvolvimento são instituições financeiras cuja principal função é a concessão de crédito de longo prazo, normalmente subsidiado pelo governo. Preenchem uma lacuna que não seria atendida pelo livre mercado (De Aghion, 1999). Essas instituições tiveram papel importante nos processos de industrialização de alguns países e atualmente sua atuação tem maior evidência nos países em desenvolvimento.

No caso Brasil, o BNDES contribui para a promoção do crescimento da economia. Criado em 1952, durante o segundo governo de Getúlio Vargas, é um banco estatal que figura como uma das maiores agências de fomento do mundo (Hirt, 2013).

O BNDES desempenha o papel de agente financiador de longo prazo, presente em praticamente todos os setores da economia brasileira, com empréstimos vinculados a gastos com finalidades específicas, como projetos de investimento, exportação de manufaturados e serviços, entre outros.

Para subsidiar esses empréstimos, o BNDES realiza operações que podem ocorrer diretamente pelo banco (em financiamentos com valor superior a $\mathrm{R} \$ 10$ milhões) ou, de forma indireta, por meio de instituições financeiras credenciadas. Nas operações indiretas, a análise do financiamento é feita pela credenciada, que assume o risco de não pagamento da operação. Por isso, a instituição pode aceitar ou não o pedido de crédito. É ela também que negocia com o cliente as condições do financiamento, como prazo de pagamento e garantias exigidas, 
respeitando algumas regras e limites definidos pelo BNDES (Banco Nacional de Desenvolvimento Econômico, 2020).

Para realizar essas operações, o banco utiliza os recursos provenientes do Fundo de Amparo ao Trabalhador (FAT), do Tesouro Nacional, do Fundo da Marinha Mercante (FMM), do Fundo de Garantia do Tempo de Serviço (FGTS) e de seu fundo de investimento (FI-FGTS) - captações externas via organismos multilaterais ou emissão de títulos (bonds) e emissões privadas de Letras Financeiras (Banco Nacional de Desenvolvimento Econômico, 2020).

No que concerne à taxa de juros, constata-se que, no período de 1994 a 2017, a taxa de juros utilizada nos empréstimos concedidos pelo BNDES era a Taxa de Juros de Longo Prazo $(\text { TJLP })^{9}$, que é calculada com base nos seguintes parâmetros: i) meta de inflação calculada pro rata para os 12 meses seguintes ao primeiro mês de taxa de aplicação, ainda que com base nas metas anuais estabelecidas pelo Conselho Monetário Nacional (CMN); ii) prêmio de risco (Oliveira, 2016a).

De acordo com DIEESE (Departamento Intersindical de Estatística e Estudos Socioeconômicos, 2017), a existência da TJLP justificava-se pelas seguintes razões: evitar que investimentos produtivos sejam penalizados pela elevada taxa básica de juros (Selic); aumentar a competitividade da indústria de bens de capital com elevado conteúdo nacional; evitar excessiva dolarização do balanço das empresas brasileiras.

Desse modo, o crédito do BNDES pode tornar-se mais atrativo do que o crédito disponível no mercado financeiro estritamente privado, pois o BNDES promove o financiamento com um prazo maior, cobrando taxas abaixo do mercado, com base no custo menor proporcionado pelo FAT, maior provedor de recursos do BNDES. Já nos mercados estritamente privados, as taxas de juros são maiores que as praticadas pelo BNDES e os prazos e as demais condições dos empréstimos são determinados pelo banco credor ou estabelecidos por meio de negociações entre a instituição financeira e o tomador de crédito, com base em recursos supridos pelo mercado (Morais, 2008).

\subsection{Referencial empírico}

No Brasil, vários estudos analisaram os impactos dos desembolsos do BNDES, principal fonte de financiamento de longo prazo em moeda local. Em meio a esses estudos, destacamse os que enfatizam o impacto dos desembolsos do BNDES sobre a geração de emprego, como Pereira (2007), Ribeiro \& De Negri (2009), Coelho \& De Negri (2010), Machado et al. (2011), Maffioli et al. (2016). O Quadro 1 foi construído com base nos trabalhos anteriormente mencionados e permite ter uma visão resumida dos estudos realizados.

Por meio dos trabalhos citados, pode-se verificar que, no caso do BNDES, a avaliação de desempenho consiste no acompanhamento dos desembolsos do banco; a avaliação de impacto seria medida, por exemplo, pela ampliação da capacidade produtiva do país ou de sua infraestrutura; por último, a avaliação de efeitos poderia medir alterações no mercado de trabalho. Portanto, a avaliação diz respeito a efeitos da ação do BNDES, tendo-se em vista que a influência no mercado de trabalho não é atividade primária do banco, sendo, portanto, efeito indireto de sua ação sobre o meio social/institucional (Pereira, 2007).

\footnotetext{
9 Em 2017, o Congresso Nacional aprovou a Medida Provisória no 777/2017, que instituiu a Taxa de Longo Prazo (TLP) como base para os financiamentos concedidos pelo BNDES, em substituição à TJLP. A TLP é definida pelo Índice de Preços ao Consumidor Amplo (IPCA), mais a taxa de juro real da NTN-B de cinco anos (média trimestral). Essa taxa entrou em vigor nos contratos iniciados a partir de janeiro de 2018 (Bastos, 2017). A mudança implementada na taxa de juros utilizada pelo BNDES tem por objetivo aproximar as taxas de juros praticadas pelo BNDES a dos mercados estritamente privados (Banco de Desenvolvimento do Extremo Sul, 2020).
} 
Quadro 1. Resumo dos principais estudos acerca da avaliação de impacto dos desembolsos do BNDES

\begin{tabular}{|c|c|c|c|}
\hline Autor(es) & Objetivo & Modelo/metodologia & Variáveis \\
\hline \multirow{3}{*}{ Pereira (2007) } & \multirow{3}{*}{$\begin{array}{c}\text { Comparar o } \\
\text { desempenho em } \\
\text { termos de emprego } \\
\text { das empresas } \\
\text { apoiadas pelo BNDES } \\
\text { em relação ao } \\
\text { restante de empresas } \\
\text { não apoiadas de } \\
\text { mesmo porte. }\end{array}$} & $(2)=T_{p|s| r, 2001}^{n a^{*}}=T_{p|s| r, 1999}^{n a^{*}} X \frac{T_{p|s| r, 2001}^{n a}}{T_{p|s| r, 1999}^{n a}}$ & $\begin{array}{c}T_{p \mid s}^{n a^{*}} \text {, }=\text { número de } \\
\text { trabalhadores do } \\
\text { grupo de controle de } \\
\text { estabelecimentos não } \\
\text { apoiados no ano t, que } \\
\text { pertencem ao mesmo } \\
\text { grupo porte/setor/região }\end{array}$ \\
\hline & & \multirow[b]{2}{*}{$\begin{array}{c}\text { Modelo de geração de empregos do } \\
\text { BNDES }\end{array}$} & $\begin{array}{l}\frac{T_{p|s| r, 1999}^{n a}}{E_{p|s| r}^{n a}}=\text { número } \\
\text { médio de trabalhadores } \\
\text { dos estabelecimentos não } \\
\text { apoiados que pertencem } \\
\text { ao mesmo grupo porte/ } \\
\text { setor/região }\end{array}$ \\
\hline & & & $\begin{array}{l}\frac{T_{p|s| r, 2001}^{n a}}{T_{p|s| r, 1999}^{n a}}=\text { taxa de } \\
\text { crescimento do número } \\
\text { de trabalhadores dos } \\
\text { estabelecimentos não } \\
\text { apoiados que pertencem } \\
\text { ao mesmo grupo porte/ } \\
\text { setor/região }\end{array}$ \\
\hline \multirow[b]{2}{*}{$\begin{array}{l}\text { Ribeiro \& De } \\
\text { Negri (2009) }\end{array}$} & \multirow[b]{2}{*}{$\begin{array}{l}\text { Avaliar o efeito } \\
\text { do crédito } \\
\text { público sobre a } \\
\text { produtividade, } \\
\text { observando } \\
\text { empresas de } \\
\text { fabricação que } \\
\text { inovam no Brasil. }\end{array}$} & Public $_{\text {it }}=\alpha+\beta$ Small $_{i t}+\beta_{2}$ Treat $_{i}+\beta_{3}$ D2003 $+\gamma_{l}\left(\right.$ Treat $_{i}{ }^{*}$ D2003 $)+\varepsilon_{\text {it }}$ & \multirow[b]{2}{*}{$\begin{array}{c}\text { Public }_{\text {it }}=\text { dummy } \\
\text { que indica se obteve } \\
\text { crédito para financiar a } \\
\text { inovação em máquinas; } \\
\text { Small }_{\text {it }} \text { = dummy } \\
\text { que indica se uma } \\
\text { empresa é classificada } \\
\text { como pequena ou } \\
\text { não; Treat = é igual } \\
\text { a } 1 \text { se a empresa } \\
\text { mudar a categoria de } \\
\text { classificação de tamanho } \\
\text { devido à alteração da } \\
\text { norma; D2003 = dummy } \\
\text { para } 2003\end{array}$} \\
\hline & & Diferença em diferenças & \\
\hline \multirow[b]{2}{*}{$\begin{array}{l}\text { Coelho \& De } \\
\text { Negri (2010) }\end{array}$} & \multirow[b]{2}{*}{$\begin{array}{l}\text { Estima o impacto } \\
\text { do financiamento } \\
\text { do BNDES sobre } \\
\text { indicadores de } \\
\text { desempenho de } \\
\text { firmas financiadas. }\end{array}$} & $P T F=[\operatorname{Ln}(r l v)-\operatorname{Ln}(k) s(k)+\operatorname{Ln}(w) s(w)+\operatorname{Ln}(m a t) s(m a t)]$ & \multirow[b]{2}{*}{$\begin{array}{c}\text { Em que i rlv é a receita } \\
\text { líquida de vendas, wi } \\
\text { é o gasto total com } \\
\text { pessoal, mati é o } \\
\text { gasto com insumos } \\
\text { utilizados na produção, } \\
\text { como energia } \\
\text { elétrica, materiais } \\
\text { e combustíveis, ki } \\
\text { representa o valor } \\
\text { do estoque de capital } \\
\text { fixo produtivo e a } \\
\text { função s(x) representa } \\
\text { a proporção do gasto } \\
\text { com x em relação ao } \\
\text { gasto total }\end{array}$} \\
\hline & & $\begin{array}{l}\text { Efeito quantílico de tratamento } \\
\text { (EQT)/propensity score }\end{array}$ & \\
\hline
\end{tabular}


Quadro 1. Continuação...

\begin{tabular}{|c|c|c|c|}
\hline Autor(es) & Objetivo & Modelo/metodologia & Variáveis \\
\hline $\begin{array}{l}\text { Machado et al. } \\
\qquad(2011)\end{array}$ & $\begin{array}{c}\text { Avaliar o impacto } \\
\text { do uso do cartão } \\
\text { BNDES sobre o } \\
\text { crescimento do } \\
\text { emprego nas } \\
\text { empresas que } \\
\text { utilizaram esse } \\
\text { crédito para a } \\
\text { realização de } \\
\text { aquisições durante } \\
2008 \text {. }\end{array}$ & $\mid \begin{array}{c}\begin{array}{c}\ln (\text { estoque empregado })_{i t}=\beta_{0} \\
+\beta_{1} \text { periodo }_{t}+ \\
\beta_{2} \text { tratamento }_{i}+\beta_{3} \text { periodo }_{t} * \text { tratamento }_{i}+u_{i}\end{array}\end{array}$ & $\begin{array}{l}\text { Ln (estoque } \\
\text { empregados): logaritmo } \\
\text { natural do número de } \\
\text { empregados; período: } \\
\text { dummy com valor } 1 \\
\text { para firmas no período } \\
\text { pós-tratamento } \\
\text { e } 0 \text { no período } \\
\text { pré-tratamento; } \\
\text { tratamento: dummy } \\
\text { com valor } 1 \text { para o } \\
\text { grupo de tratamento } \\
\text { e } 0 \text { para grupo de } \\
\text { controle; período } \\
\text { *tratamento: valor } 1 \\
\text { para as firmas tratadas } \\
\text { no período pós- } \\
\text { tratamento e } 0 \text { para as } \\
\text { demais observações; u: } \\
\text { termo de erro }\end{array}$ \\
\hline \multirow[b]{2}{*}{$\begin{array}{l}\text { Maffioli et al. } \\
\qquad(2016)\end{array}$} & & $Y_{i t}=\alpha_{i}+\mu_{t}+\beta T_{i t}+\gamma X_{i t}+\varepsilon_{i t}$ & \multirow[b]{2}{*}{$\begin{array}{c}\text { Yit: resultado da } \\
\text { empresa i no ano t } \\
\text { (emprego, exportação } \\
\text { e diferencial de salário); } \\
\text { } \mu \text { t representa choques } \\
\text { anuais que afetam } \\
\text { todas as empresas; Tit } \\
\text { é uma variável binária } \\
\text { que leva o valor } 1 \\
\text { desde o ano em que } \\
\text { a empresa entra no } \\
\text { programa; Xit é um } \\
\text { vetor de variação do } \\
\text { tempo e cit é o termo } \\
\text { de erro }\end{array}$} \\
\hline & $\begin{array}{c}\text { Analisa o } \\
\text { impacto das } \\
\text { linhas de crédito } \\
\text { administradas } \\
\text { pelo BNDES e pela } \\
\text { Finep no fomento } \\
\text { do emprego das } \\
\text { empresas. }\end{array}$ & Diferença em diferenças & \\
\hline & & & \\
\hline
\end{tabular}

\section{Metodologia}

No intuito de avaliar o impacto dos desembolsos do BNDES sobre o crescimento do emprego nas empresas que fazem parte da agroindústria e que receberam financiamento no período de 2009 e 2010, período em que foi implementada a política anticíclica, foram utilizados dois métodos analíticos: PSM e DID. Na primeira etapa, utilizou-se o PSM, uma técnica de pareamento que buscou construir um grupo de controle adequado com base nas características anteriores à política anticíclica, selecionando empresas que sejam similares àquelas que receberam financiamento (grupo de tratamento). Em um segundo momento, o método DID foi empregado para comparar os resultados do grupo de tratamento e de controle, antes e depois da intervenção. A utilização conjunta desses dois métodos permitiu controlar as empresas avaliadas por suas condições iniciais, minimizando a existência de viés de seleção. 


\subsection{Propensity score matching (PSM)}

O método PSM compara indivíduos que participaram de determinada política (no caso deste estudo, as empresas da agroindústria que foram beneficiárias dos financiamentos do BNDES) denominados de grupo de tratamento, com indivíduos que não participaram da política (empresas da agroindústria que não receberam financiamento do BNDES) ou grupo controle.

O matching, por meio do propensity score, é essencialmente um método de ponderação, que, por sua vez, determina quais serão os pesos atribuídos aos indivíduos do grupo de controle na estimação do efeito do tratamento. Consiste no pareamento de unidades com base no propensity score, que, a partir de um vetor de covariáveis não afetadas pelo tratamento, estima-se um escore ou índice de propensão (propensity score) para parear os participantes com os não participantes de um determinado programa (Khandker et al., 2010). No PSM, cada participante é pareado com um não participante baseado num único propensity score, que reflete a probabilidade de participação condicionada às diferentes características observáveis. Segundo Rosenbaum \& Rubin (1983), a medida de probabilidade condicional de participação no tratamento, dado o vetor $x$, é denotada por $p(x)$, em que:

$p(x)=\operatorname{Pr}[D=1 \mid X=x]$

A medida do propensity score pode ser computada se tomados os dados $\left(D_{i}, x_{i}\right)$, em que $D=\{0,1\}$ é o indicador da exposição do tratamento e consiste no vetor de características observadas. O propensity score é um valor de balanceamento no sentido em que a distribuição condicional de $x$, denotada $p(x)$, é independente do tratamento.

O PSM consiste em uma forma de realizar comparação direta entre os grupos de tratamento e controle para verificar os efeitos de determinado tratamento. Esse procedimento consiste em duas etapas: a medição do escore de propensão e o cálculo do efeito médio do tratamento nos tratados (ATT) (Wegelin, 2014).

O PSM faz o pareamento nos escores de propensão em vez de fazê-lo diretamente nos regressores (Rosenbaum \& Rubin, 1983). O pareamento é feito controlando-se pelas covariáveis usando uma função particular delas, especificamente a probabilidade condicional de tratamento, ou seja, faz-se o pareamento sobre o escore de propensão, que pode ser calculado por uma regressão Logit ou Probit. O pareamento exato, ou seja, dois indivíduos com o mesmo escore, não é possível, sendo as unidades de comparação utilizadas aquelas para as quais os escores estão mais próximos à unidade tratada (Schuntzemberger et al., 2015).

Para fins deste estudo, o status de tratamento das empresas da agroindústria é representado por uma variável dummy (T), que tem valor " 1 ", se recebeu crédito do BNDES, e valor " 0 ", para as empresas da agroindústria que não receberam empréstimo do BNDES no período.

O impacto médio do tratamento sobre as empresas "tratadas" (ATT) é dado por

$$
A T T=E\left[Y_{i}^{1}-Y_{i}^{0} \mid T_{i}=1\right]=E\left(Y_{i}^{l} \mid X, T_{i}=1\right)-E\left(Y_{i}^{0} \mid T_{i}=1\right)
$$

Contudo, a estimativa do escore de propensão não é suficiente para estimar o efeito médio do tratamento, pois a probabilidade de encontrar duas empresas com o mesmo escore de propensão é, em princípio, 0 , dado que $p(X)$ é uma variável contínua. Dessa forma, vários métodos são propostos para lidar com esse problema, como o método de pareamento por vizinhos mais próximos, por estratificação, por raio e por Kernel (Becker \& Ichino, 2002).

O pareamento pelo vizinho mais próximo consiste em procurar, para cada unidade tratada, a unidade de controle com o escore de propensão mais próximo. Uma vez que cada unidade 
tratada é pareada com uma unidade de controle, a diferença entre a saída da unidade tratada e de controle a ela pareada é calculada. O efeito do tratamento nos tratados (ATT) é obtido pela média dessas diferenças (Paredes, 2016).

O pareamento por estratificação consiste em dividir o intervalo de variação do escore de propensão em subintervalos, de modo que, em cada subintervalo, unidades tratadas e de controle tenham, na média, o mesmo escore de propensão. Dentro de cada subintervalo em que unidades tratadas e de controle estão presentes, a diferença entre a média das saídas delas é computada. O ATT é obtido pela média dos ATTs de cada bloco com pesos dados pela distribuição de unidades tratadas através dos blocos (Wegelin, 2014).

No pareamento por raio, cada unidade tratada é pareada apenas com as unidades de controle, cujos escores de propensão estejam dentro de um raio de vizinhança prédefinido do escore de propensão da unidade tratada. Quanto menor o tamanho do raio, melhor a qualidade do pareamento (Wegelin, 2014). No pareamento por kernel, todos os tratados são pareados com uma média ponderada de todos os controles. A ponderação é inversamente proporcional à distância entre o escore de propensão dos tratados e controles (Wegelin, 2014).

\subsection{Diferenças em diferenças (DID)}

O estimador DID se aplica, sobretudo, a delineamentos quase experimentais e requer informação tanto do grupo controle como dos tratados em, pelo menos, dois períodos (antes e depois da intervenção). A hipótese por trás do método é a de que, controlando por um conjunto de variáveis observáveis, caso o tratamento não tivesse efeito algum, a trajetória dos resultados entre tratados e não tratados deveria evoluir paralelamente. Assim, qualquer efeito do tratamento seria capturado pela diferença dos resultados antes e após a intervenção do programa avaliado (Lechner, 2011).

O método DID estima o impacto médio do programa da seguinte forma:

$D I D=E\left(Y_{1}^{T}-Y_{0}^{T} \mid D_{1}=1\right)-E\left(Y_{1}^{C}-Y_{0}^{C} \mid D_{1}=0\right)$

em que $D_{1}=1$ representa a presença do programa (grupo de tratados) e $D_{1}=0$, o grupo de não tratados, $\mathrm{t}=0$ é o período antes da política e $\mathrm{t}=1$, o período após a implementação da política; $Y_{t}^{T}$ e $Y_{t}^{C}$ representam, respectivamente, o resultado para os participantes e não participantes do programa, no tempo t. Com dados de participantes e não participantes antes da implementação da política e também depois da intervenção, a diferença é calculada entre os resultados médios observados para os grupos de tratamento e de controle antes e depois da intervenção da política (Khandker et al., 2010).

Lee (2005) apresenta uma segunda equação do impacto médio do DID, que, além de ser análoga à primeira, considera o problema do contrafactual.

$D I D=E\left(Y_{t 1}^{T}-Y_{t 0}^{C} \mid D=1\right)-E\left(Y_{t 1}^{C}-Y_{t 0}^{C} \mid D=0\right)$

Nesta equação, $Y_{t 1}^{T}, Y_{t 1}^{C}$ e $Y_{t o}^{C}$ representam os resultados potenciais dos grupos de tratamento e controle em $t_{l}$ e $t_{0}$, respectivamente.

O DID pode ser aplicado por meio da especificação de uma equação, estimada por mínimos quadrados ordinários. A equação básica do modelo assume a seguinte forma: 
$Y_{i t}=\alpha+\beta T_{i t} t+\rho T_{i t}+\gamma t+\varepsilon_{i t}$

em que Té uma variável binária que assume valor 1, se a empresa é tratada, e 0, caso contrário; té uma variável binária que assume valor 1 no período pós-política e valor 0 , caso contrário. O termo de erro é dado por $\varepsilon_{i t}$. As variáveis correspondentes ao período de tempo e ao status de tratamento são incluídas separadamente, para captar os efeitos médios do tempo sobre a medida de resultado, assim como o efeito da unidade fazer parte do grupo de tratados ou não.

A introdução do termo de interação na equação procura captar o que ocorreu especificamente com o grupo de tratamento no período pós-política, ou seja, se a média da variável de resultado para esse grupo em particular tornou-se diferente após a intervenção. A função do termo de interação é captar o impacto da política que é medido por $\beta$.

\subsection{Base de dados e especificações}

Para este estudo, foram utilizadas as séries anuais das variáveis entre 2008 e 2010, que compreendem o período de expansão dos desembolsos do BNDES em virtude da política anticíclica adotada pelo governo em 2009. Esse intervalo se encaixa na pré e na pós-política anticíclica, o que pode influenciar a contratação de empregados.

As unidades de interesse deste trabalho são as empresas da agroindústria, ou seja, pretende-se saber se os estabelecimentos receberam ou não crédito do BNDES. Sendo assim, para verificar o impacto sobre o emprego, é necessário utilizar os microdados da RAIS. A RAIS disponibiliza em seu sítio apenas informações agregadas por municípios, em razão do compromisso de sigilo da unidade informante. Por conseguinte, solicitou-se ao Ministério de Trabalho a base de dados da RAIS identificada que contém dados no âmbito das empresas. Esses dados foram solicitados considerando apenas as empresas da agroindústria, em sentido amplo, para realizar uma análise que pudesse captar os efeitos dos desembolsos do BNDES no âmbito das empresas para esse segmento produtivo.

Para a geração dos grupos de controle (empresas não financiadas) e tratamento (empresas financiadas), foram utilizadas duas bases de dados, a RAIS identificada e os dados do BNDES referentes às contratações das firmas que receberam empréstimos no período analisado, seja diretamente pela instituição, seja indiretamente por meio de bancos públicos e/ou privados. O elemento em comum entre essas duas bases foi o CNPJ das empresas, de forma que as duas bases puderam ser concatenadas, gerando, assim, os grupos de interesse. Essa concatenação foi realizada para os anos em análise: 2008, 2009 e 2010.

Para construir uma amostra balanceada, foram consideradas nas estimações empresas que possuem informações na RAIS nos três anos em análise. Todas as empresas que não possuíam dados nos três anos foram excluídas da amostra. Sendo assim, do universo de 108.949 firmas da agroindústria presentes na RAIS em 2008, 76.739 possuíam informações referentes aos dados de emprego em todos os anos da análise. No que concerne aos dados das empresas que receberam financiamento do BNDES em 2009 e 2010, foi possível identificar 4.327 empresas, por meio dos dados da RAIS, das 7.036 empresas beneficiadas.

Para cálculo do escore de propensão, foram identificados as variáveis de tratamento e o vetor de características observáveis das empresas. A variável de tratamento é representada por uma dummy $(D i)$, em que 1 indica se a empresa recebeu financiamento e 0 se a empresa não o recebeu. As variáveis de controle foram consideradas no ano-base da regressão, isto é, do primeiro ano do intervalo. São elas: anos de escolaridade média dos trabalhadores (ESCMED); 
idade média dos trabalhadores (IDADEMED); dummy para as macrorregiões do país; dummy de porte da empresa (PORT); PIB per capita.

A variável PORT define o porte da empresa em termos do número de funcionários. De acordo com o Departamento Intersindical de Estatística e Estudos Socioeconômicos (DIEESE) e o Serviço Brasileiro de Apoio às Micro e Pequenas Empresas - Sebrae (Serviço Brasileiro de Apoio às Micro e Pequenas Empresas, 2013), as firmas podem ser classificadas como pequenas, médias e grandes empresas de acordo com o setor. No caso da indústria, as pequenas empresas são definidas como aquelas com até 49 funcionários, as médias são aquelas que possuem de 50 a 99 funcionários e as grandes empresas são aquelas com número de funcionários superior a 100. A utilização dessa variável está em consonância com os estudos de Oliveira et al. (2015), Daniel (2016) e Silva \& Saccaro (2019).

A variável ESCMED define o nível de escolaridade do conjunto de funcionários das empresas que fazem parte da agroindústria; representa o nível de qualificação em uma determinada empresa. A utilização dessa variável está em conformidade com os estudos de Coelho \& De Negri (2010) e Lobo (2012).

As regiões também foram consideradas no modelo. As variáveis sul, sudeste, norte, nordeste e centro-oeste são um conjunto de variáveis dicotômicas que identificam a região onde está localizada a empresa. A inclusão dessas variáveis se justifica por captarem as disparidades regionais em razão de a economia apresentar trajetória divergente em cada região por uma série de características locais, como acesso a mercados, matérias-primas e transportes. As variáveis foram utilizadas baseadas nos estudos de Oliveira et al. (2015), Daniel (2016), Schuntzemberger (2016) e Silva \& Saccaro (2019).

A variável IDADEMED define a idade média do conjunto de funcionários das empresas que fazem parte do segmento da agroindústria. A utilização dessa variável está em conformidade com os estudos de Soares et al. (2014), Daniel (2016) e Silva \& Saccaro (2019).

A variável PIB per capita do município onde se localiza a firma foi inclusa no modelo com o objetivo de captar a dinâmica da economia local que pode influenciar a geração de emprego e renda e o nível de produtividade. A utilização dessa variável está de acordo com os estudos de Soares et al. (2013) e Daniel (2016).

Vale ressaltar que foi utilizada na estimação a métrica dos cinco vizinhos mais próximos ${ }^{10}$, em virtude de apresentar o melhor ajustamento do modelo. Essa métrica também foi responsável pelo pareamento da amostra. Com a imposição do suporte comum, a amostra pareada contou com 3.524 empresas no grupo de tratamento e 49.956 empresas no grupo de controle. Essa amostra foi utilizada tanto na estimação do PSM quanto do DID.

Para estimar o efeito da política, utilizou-se o método de diferenças em diferenças. Para esse trabalho, a equação foi especificada como

$Y_{i t}=\beta_{0}+\beta_{1}{\text { Fin } B N D E S_{i}}+\beta_{2}$ ano $_{t}+\beta_{3}\left(\right.$ Fin BNDES $\left._{i} x a n o_{t}\right)+\beta_{4 \text { cov }}+\varepsilon_{i t}$

em que $Y_{i t}$ se refere ao resultado de interesse (estoque de emprego) da empresa $i$ no ano $t$, Fin $B N D E S_{i}$ é uma variável que assume valor igual a 1 se a empresa recebeu financiamento e 0 , caso contrário; a variável ano $_{t}$ assume valor 0 quando $t=0$ (antes da implementação da

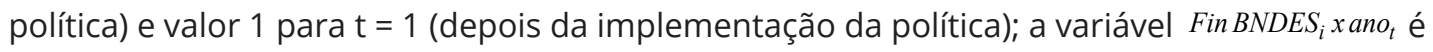
uma interação das variáveis anteriores que assume valor 1 apenas para as empresas do grupo de

${ }^{10}$ Com Propensity Score estimado para toda a unidade da amostra, procedeu-se à aplicação do algoritmo dos cinco vizinhos mais próximos, em que se realizou o pareamento das empresas tratadas com as cinco empresas do grupo de controle mais semelhantes em características observáveis, ou seja, com escores de propensão mais próximos. 
tratamento no período depois da implementação da política. Nessa regressão, pode-se mostrar que o coeficiente $\beta_{3}$, associado à interação, é justamente o impacto dos financiamentos do BNDES sobre o crescimento do emprego em empresas financiadas.

A variável de desempenho desse estudo foi o estoque de emprego. A escolha dessa variável foi delimitada pelas informações da RAIS, também tendo sido utilizada por Soares et al. (2009, 2014) e Machado et al. (2011). As demais variáveis explicativas do modelo incluídas como controles são as mesmas utilizadas no modelo PSM.

Essas variáveis foram importantes para estimar o modelo de avaliação da política de crédito do BNDES, pois representam as características tanto em nível de empregados como em nível de atributos dos estabelecimentos das empresas da agroindústria presentes nos municípios brasileiros.

Destaca-se que a especificação do modelo foi realizada na forma logarítmica, por aproximar a distribuição do estoque de empregados das firmas de uma distribuição normal. De acordo com Machado et al. (2011), essa aproximação permite lidar com problemas de outliers na estimação dos efeitos médios do tratamento e também atribui maior grau de validade na realização da inferência nas estimativas do modelo.

\section{Resultados}

\subsection{Estatística descritiva da amostra}

A estatística descritiva das variáveis utilizadas na análise do modelo é apresentada na Tabela 2, onde se verificam as características das empresas que receberam financiamento (grupo de empresas tratadas) e das empresas que não receberam financiamento (grupo de empresas controle). O objetivo é comparar esses grupos em termos das variáveis utilizadas nos modelos estimados antes de participar da política para identificar o grau de heterogeneidade preexistente entre elas.

Por meio dos resultados, constata-se que tanto no grupo tratado como no grupo controle a maior parte das empresas da agroindústria se localiza nas regiões Sul e Sudeste. Em média, 85\% dos dados analisados são constituídos por micro e pequenas empresas e $62 \%$ das financiadas pelo BNDES são micro e pequenas empresas com até 49 empregados. Pode-se observar também que tanto a idade média quanto os anos de estudos apresentaram-se semelhantes entre os dois grupos.

Tabela 2. Estatísticas das variáveis explicativas do modelo considerando as empresas pertencentes ao grupo de tratado e controle no ano-base da análise (2008)

\begin{tabular}{ccccc} 
Variáveis & Tratado & $\%$ & Controle & $\%$ \\
Total de empresas & 3.524 & - & 49.956 & - \\
Regiões & - & - & - & - \\
Norte & 129 & 3,7 & 1.763 & 3,5 \\
Nordeste & 271 & 7,7 & 6.623 & 13,3 \\
Sul & 1.537 & 43,6 & 15.983 & 32,0 \\
Sudeste & 1.362 & 38,6 & 21.923 & 43,9 \\
Centro-Oeste & 225 & 6,4 & 3.664 & 7,3 \\
Porte das empresas & - & - & - & - \\
Pequeno & 2.190 & 62,1 & 44.035 & 88,1 \\
Médio & 533 & 15,1 & 2.990 & 6,0 \\
Grande & 801 & 22,7 & 2.931 & 5,9 \\
Idade média dos empregados & 33 & - & 34 & - \\
Escolaridade média (anos) & 11 & - & 11 & - \\
\hline
\end{tabular}

Fonte: elaboração própria. 
Após essa análise, partiu-se, então, para a estimativa do método PSM. O pareamento realizado por meio dessa técnica selecionou empresas do grupo de controle mais similares às tratadas de forma que o impacto da política fosse estimado sem a presença de viés. O resultado desse procedimento é exposto na subseção seguinte.

\subsection{Resultados do modelo PSM}

Para identificar o impacto da política de crédito do BNDES implementada na economia brasileira como uma das medidas da política anticíclica sobre a geração de emprego nas empresas da agroindústria, estima-se, inicialmente, a probabilidade de recebimento do tratamento tanto para os participantes quanto para os não participantes da política. Sendo assim, realizou-se o cálculo do escore de propensão que foi estimado pelo modelo Probit condicionado às características observáveis no período anterior ao tratamento (ano-base). A variável dependente binária corresponde ao fato de a empresa ter ou não recebido financiamento, a fim de mensurar a probabilidade de as empresas obterem crédito do BNDES.

No que concerne aos resultados do modelo (Tabela 3), pode-se constatar que quanto maior a escolaridade dos funcionários, maior a probabilidade de a empresa acessar o crédito do BNDES. Esse resultado corrobora com Maffioli et al. (2016), em que os autores, com base em um modelo Probitindividual, concluíram que empresas mais maduras, com mais funcionários qualificados e mais gastos salariais, tinham mais probabilidade de participar de programas de crédito público.

Esse resultado também se observa em Aoki \& Badalotti (2014), em que os autores realizaram uma análise sobre o acesso à linha de crédito BNDES/Finame e constataram que todos os empresários que acessaram a referida linha possuíam escolaridade acima de $2^{\circ}$ grau completo.

Uma possível justificativa para isso se dá em virtude de que quanto maior o grau de escolaridade dos funcionários, maior será o nível de sofisticação do processo produtivo, o grau de utilização do capital da empresa e o conhecimento acerca da oferta de linhas de crédito e dos procedimentos necessários à obtenção deste (Carrer et al., 2013).

A variável PIB per capita do município também se apresentou relevante na probabilidade de acessar o crédito, porém com sinal negativo, indicando que quanto maior o PIB per capita do município, menor a probabilidade de acessar o financiamento do BNDES. Tal constatação está de acordo com os resultados obtidos por Soares et al. (2009) e Soares et al. (2013), que, ao analisarem a probabilidade de as empresas acessarem o crédito do Fundo Constitucional do Nordeste, verificaram que empresas localizadas em municípios com menor PIB per capita possuem mais probabilidade de acessar o crédito.

Em relação aos resultados das variáveis indicadoras das regiões, verifica-se um fato importante. Como a categoria omitida é a região Sul, por apresentar o maior número de empresas em ambos os grupos, as empresas localizadas nas regiões Sudeste, Centro-oeste, Norte e Nordeste apresentaram menos probabilidade de receber financiamento do que em relação a essa região. Esse fato pode ser justificado pela importância da agroindústria para a economia da região Sul, dado que essa região concentra grande parta da produção, estrutura produtiva e estoque de emprego desse segmento produtivo. Tal fato está de acordo com Silva \& Saccaro (2019), que mostraram que o fato de as empresas estarem instaladas no Sul do país aumenta suas chances de receber empréstimos em relação às empresas instaladas nas regiões Nordeste e Centro-Oeste.

No que concerne ao porte das empresas, verifica-se que tanto as empresas de grande como de médio porte têm mais probabilidade de receber financiamento em relação às de pequeno porte 
(variável omitida). Sendo assim, pode-se averiguar que o aumento do tamanho das empresas possui impacto positivo sobre a probabilidade de acessar o crédito do BNDES. Esse resultado também o estudo de Silva \& Saccaro (2019) que, ao analisar os empréstimos do BNDES, verificaram que estes foram concedidos em maior proporção para empresas com mais funcionários e concluíram que quanto maior o tamanho da firma, maior o valor médio desses empréstimos.

Estudos apontam que a falta de garantias, de avalista e de informações confiáveis sobre o negócio é apontada como o principal obstáculo ao acesso ao crédito para as empresas de pequeno porte, dado que os agentes financeiros não conseguem determinar os riscos de forma tão clara, pois empresas desse porte têm relativamente menos garantias reais para assegurar o empréstimo e mais risco de default do que as empresas médias e grandes. Além desse problema de assimetria de informação, altas taxas de juros são outro obstáculo apontado pelos empresários como restrição de acesso ao crédito (Machado et al., 2011; Zica \& Martins, 2008).

Em geral, os resultados do modelo Probit apontam que a probabilidade de as empresas da agroindústria acessarem o crédito do BNDES está vinculada tanto a fatores locacionais quanto a variáveis como PIB per capita, grau de instrução e porte das firmas.

Tabela 3 Estimativa dos coeficientes do modelo Probit

\begin{tabular}{cc} 
Variáveis & Coeficientes \\
\hline Idade Média & $-0,0007^{\star}$ \\
Dnorte & $-0,2175^{\star}$ \\
Dsudeste & $-0,2210^{*}$ \\
Dcentro-oeste & $-0,2438^{*}$ \\
Dnordeste & $-0,2606^{*}$ \\
Mporte & $0,6135^{\star}$ \\
Gporte & $0,8595^{*}$ \\
PIBpc & $-0,0400$ \\
Analfabeto (\%) & 0,0005 \\
Ensino fundamental (\%) & $-0,0001^{*}$ \\
Ensino médio (\%) & $-0,0007^{\star \star}$ \\
Ensino superior & $0,0082^{*}$ \\
Constante & $-1,1245^{*}$ \\
\hline
\end{tabular}

*Significativo em nível de $1 \%$ de probabilidade. ** Significativo em nível de $5 \%$ de probabilidade. Fonte: elaboração própria.

Embora tais resultados possam contribuir para uma análise qualitativa de distribuição de recursos, no contexto da avaliação de impacto, o objetivo é a geração de escores de crédito consistentes que sintetizem as características das empresas e possam ser utilizados para o pareamento e a comparação dos desempenhos das empresas que receberam não créditos do BNDES.

Para constatar se o modelo PSM está balanceado, é preciso verificar o teste de balanceamento das covariáveis que afetam o modelo especificado, o qual consiste em verificar a diferença de médias antes e depois do pareamento para os escores de propensão estimados de formas individual e conjunta. Na Tabela 4 são sintetizados os resultados das médias para cada uma das covariáveis consideradas no cálculo, separadas por grupos (tratado e controle), antes e após o pareamento. De acordo com os resultados, percebe-se que a diferença das médias de cada covariável é menor nas amostras pareadas do que nas amostras não pareadas. Isto é confirmado por meio do teste $t$, em que, para todas as covariáveis, a hipótese nula de que o valor médio de cada variável é o mesmo no grupo de tratamento e no grupo de controle após o pareamento não foi rejeitada. Esses resultados evidenciam que a condição de balanceamento foi satisfeita. 
Tabela 4. Médias das variáveis consideradas no PSM, separadas por grupos tratamento e controle, para as amostras antes e após o pareamento

\begin{tabular}{ccccc} 
Variável & Amostra & \multicolumn{3}{c}{ Média das variáveis } \\
\cline { 2 - 4 } Idade Média & NP & Tratado & Controle & $\mathbf{p}|\mathbf{t}|$ \\
& $\mathrm{P}$ & 33,053 & 33,644 & 0,000 \\
Dnorte & $\mathrm{3}, 053$ & 32,936 & 0,333 \\
& $\mathrm{NP}$ & 0,3661 & 0,3529 & 0,683 \\
Dsudeste & $\mathrm{P}$ & 0,3661 & 0,4058 & 0,387 \\
Dcentro-oeste & $\mathrm{NP}$ & 0,3864 & 0,4385 & 0,000 \\
& $\mathrm{P}$ & 0,3864 & 0,3792 & 0,529 \\
Dnordeste & $\mathrm{NP}$ & 0,0638 & 0,0733 & 0,036 \\
& $\mathrm{P}$ & 0,0638 & 0,0627 & 0,845 \\
Mporte & $\mathrm{NP}$ & 0,0769 & 0,1325 & 0,000 \\
& $\mathrm{P}$ & 0,0769 & 0,0709 & 0,339 \\
Gporte & $\mathrm{NP}$ & 0,1512 & 0,5985 & 0,000 \\
& $\mathrm{P}$ & 0,1512 & 0,1656 & 0,098 \\
PIBpc & $\mathrm{NP}$ & 0,2273 & 0,0586 & 0,000 \\
& $\mathrm{P}$ & 0,2273 & 0,2114 & 0,107 \\
Analfabetos & $\mathrm{NP}$ & 17125 & 17642 & 0,035 \\
& $\mathrm{P}$ & 17125 & 16761 & 0,231 \\
Ensino fundamental & $\mathrm{NP}$ & 0,6341 & 0,6471 & 0,839 \\
Ensino médio & $\mathrm{P}$ & 0,6341 & 0,6223 & 0,869 \\
& $\mathrm{NP}$ & 20,569 & 23,441 & 0,000 \\
& $\mathrm{NP}$ & 20,569 & 20,211 & 0,485 \\
& $\mathrm{P}$ & 32,288 & 33,413 & 0,027 \\
& $\mathrm{NP}$ & 32,288 & 32,123 & 0,789 \\
& 4,0294 & 2,1535 & 0,000 \\
& 4,0294 & 3,7521 & 0,217 \\
\hline
\end{tabular}

NP: amostra não pareada; P: amostra pareada. Obs: hipóteses do teste t: $H 0$ : valor médio de cada variável é o mesmo no grupo de tratamento e no grupo de não tratamento. $H 1$ : valor médio de cada variável é diferente no grupo de tratamento e no grupo de não tratamento. Fonte: elaboração própria com base no software Stata.

Na Tabela 5 são apresentadas as estatísticas do teste de médias de todas as covariáveis conjuntas para dar sustentação a essa condição. Por meio dos resultados apresentados, verifica-se que o teste razão verossimilhança de significância conjunta apresentou-se não significativo, indicando que não há diferenças nas características das empresas tratadas e não tratadas. Já com relação aos resultados do pseudo- $R^{2}$, que consiste em uma estimativa Probit da equação do escore de propensão nas amostras pareadas e não pareadas e do viés médio e mediana do valor absoluto das diferenças padronizadas de todas as variáveis do modelo, observa-se que os valores desses indicadores foram menores após o pareamento, indicando, assim, que as diferenças entre indivíduos do grupo de tratamento e do grupo de controle estão equilibradas. Sendo assim, pode-se concluir que o resultado do teste conjunto de médias aponta para a mesma direção do teste de médias individuais, indicando que o modelo proposto está balanceado.

Tabela 5. Balanceamento da amostra antes e depois do pareamento

\begin{tabular}{ccccc} 
& & & Viés médio & Viés mediano \\
Não pareada & 0,072 & 0,000 & 14,0 & 10,3 \\
Pareada & 0,001 & 0,505 & 2,2 & 2,0 \\
\hline
\end{tabular}

Fonte: elaboração própria com base no software Stata. 
Realizadas as estimativas do PSM pelo modelo Probite verificada a qualidade do balanceamento entre os grupos de tratamento e controle, procedeu-se à estimação do efeito médio do tratamento.

\subsection{Resultados do modelo DID}

Após a confirmação do balanceamento, para analisar o impacto dos financiamentos do BNDES no crescimento do emprego da agroindústria, estimou-se um modelo de diferenças em diferenças entre os grupos tratado (empresas que receberam financiamento) e controle (empresas que não receberam financiamento) antes e após a política. A suposição básica nesse método é que se as empresas são "iguais" em termos dessa probabilidade, a diferença observada no emprego pode ser considerada um resultado da política. Intuitivamente, esse estimador compara a evolução dos resultados de empresas tratadas com empresas não tratadas durante todo o período de observação (antes [2008] e depois [2010]) e atribui qualquer diferença à evolução ao impacto da política. A variável de desempenho selecionada nesse estudo consiste no estoque de emprego. Na Tabela 6 são ilustrados os cálculos das diferenças do estoque de emprego ao longo do tempo.

Tabela 6. Cálculo das diferenças em diferenças entre os grupos de tratamento e controle para o estoque de emprego (2008 e 2010)

\begin{tabular}{cccccc} 
& $\begin{array}{c}\text { Antes do } \\
\text { tratamento }\end{array}$ & & $\begin{array}{c}\text { Depois do } \\
\text { tratamento }\end{array}$ & & $\begin{array}{c}\text { Diferença de } \\
\text { médias }\end{array}$ \\
\cline { 2 - 3 } \cline { 5 - 5 } Empresas do grupo de tratamento & $\mathbf{2 0 0 8}$ & & $\mathbf{2 0 1 0}$ & \\
Empresas do grupo de controle & 3,311 & & 4,517 & & $0,206=4.8 \%$ \\
Diferença de médias & $1,001^{*}$ & & 3,350 & & $0,04=1.21 \%$ \\
\cline { 1 - 3 } & & $1,167 *$ & & $0,166=3.59 \%$ \\
\hline
\end{tabular}

*Significativo em nível de 1\% de probabilidade. Fonte: elaboração própria.

A primeira coluna da Tabela 6, antes do tratamento, demonstra a diferença do estoque de emprego dos grupos de controle e tratamento quando ambas as empresas não receberam financiamento. Assim, em 2008, o grupo de controle apresenta uma média menor que o grupo de tratamento. Depois, em 2010, quando as empresas do grupo de tratamento já haviam recebido financiamento, verifica-se que a diferença da média entre os grupos aumentou. Na última coluna são apresentadas as mudanças do estoque de emprego dos dois grupos em 2008 e 2010, ambos com aumento no emprego dentro do período. Por fim, foi positivo o valor das diferenças em diferenças que representa a diferença, ao longo do tempo, das diferenças da média do emprego dos dois grupos.

Sendo assim, verifica-se que as empresas da agroindústria que receberam crédito do BNDES nesse período apresentaram estoque de emprego maior em relação às empresas não beneficiárias, controlados fatores observáveis e não observáveis que afetam a dinâmica dessa variável.

Para averiguar se essa diferença é estatisticamente diferente de 0, estima-se o impacto do crédito sobre emprego. Na Tabela 7 são apresentados os coeficientes estimados na regressão para a variável dependente In (estoque de empregados). Todos os resultados são estatisticamente significativos e revelam impactos positivos dos financiamentos do BNDES para as empresas da agroindústria que receberam financiamento, ou seja, crescimento do emprego das empresas do grupo de tratamento é superior em relação ao grupo de controle. Esse fato evidencia que, no período de 2009 e 2010, para aquelas empresas que receberam financiamento do BNDES, 
os efeitos conjunturais ocasionados pela crise podem ter sido compensados em decorrência do financiamento recebido.

O impacto médio dos financiamentos do BNDES sobre o crescimento do emprego traz evidências de que as empresas agroindustriais que receberam crédito do BNDES tiveram um estoque de empregados $19,1 \%{ }^{11}$ maior do que teriam se não tivessem recebido o financiamento.

Tabela 7. Impacto do financiamento do BNDES sobre estoque de emprego na agroindústria no período de 2008 a 2010

\begin{tabular}{cccc} 
Variável & Coeficiente & Erro padrão & Valor $\mathbf{t}$ \\
Dummyfin & 0,9864 & 0,0269 & $36,56^{*}$ \\
Período & 0,0169 & 0,0077 & $2,20 * *$ \\
Impacto & 0,1750 & 0,0379 & $4,62^{*}$ \\
Constante & 2,2905 & 0,0054 & $458,36^{*}$ \\
$\mathrm{~N}=106.960$ & $p>F=0,000$ & $\mathrm{R}^{2}$ ajustado $=0,0634$ & \\
\hline
\end{tabular}

*Significativo em nível de $1 \%$ de probabilidade. ** Significativo em nível de 5\% de probabilidade. Fonte: elaboração própria.

Sendo assim, os resultados apontam que, considerando a amostra utilizada, os financiamentos do BNDES para as empresas da agroindústria poderiam ser uma política preponderante para ocasionar a geração de emprego. Em termos gerais, impactos positivos e significativos indicam que o fato de receber crédito impulsionou a geração de emprego.

Esse resultado evidencia a importância dos financiamentos do BNDES para o crescimento e o desenvolvimento da agroindústria brasileira, pois novos investimentos para empresas desse segmento produtivo podem viabilizar a expansão da produção agroindustrial e, com isso, gerar novos postos de trabalho. Além do mais, os financiamentos podem contribuir para melhorar a produtividade das empresas financiadas, ocasionando, assim, o aumento do desempenho e da competitividade.

Esse resultado está em conformidade com os estudos de De Negri et al. (2011), Machado et al. (2011), Maffioli et al. (2016) e Alves et al. (2018) que, ao analisarem o impacto dos financiamentos do BNDES sobre as firmas industriais brasileiras, constataram que o acesso ao crédito subsidiado apresentou impactos positivos sobre a geração de emprego e renda.

Portanto, por meio dos resultados apresentados, pode-se constatar que os desembolsos do BNDES para a agroindústria apresentaram impacto positivo e estatisticamente significativo no nível de emprego das empresas desse segmento produtivo, no período em que o governo utiliza mais créditos com o objetivo de conter os impactos da crise mundial na economia. Esta é, certamente, a principal conclusão produzida por este estudo, a de verificar que a agroindústria foi impactada positivamente por essa política.

Tal política também pode gerar efeitos positivos para a agroindústria a longo prazo, após o boom da liberação de crédito. A manutenção/crescimento do emprego formal pode ocorrer em virtude da maturação dos investimentos. A expansão da capacidade produtiva das empresas por meio da criação de novas plantas, ampliação de plantas existentes, restruturação e modernização de processos produtivos, inovação e desenvolvimento tecnológico (que contribui para a contratação de mão de obra qualificada, aumentando a sinergia entre os colaboradores e estimulando a pesquisa e o desenvolvimento), amplia a oferta de serviços das empresas, aumentando a demanda por insumos e serviços, elevando a produção, gerando,

${ }^{11}$ Conforme utilizado em Machado et al. (2011), o coeficiente da variável Impacto foi transformado, por meio da equação $\% \widehat{\Delta_{v}}=100^{*}\left\{\exp \left(\widehat{\beta}_{i}\right)-1\right\}$.., para medir o percentual exato do impacto estimado sobre o estoque médio de empregados (Wooldridge, 2002, p. 180). 
consequentemente, crescimento continuado de emprego, renda e aumento de produtividade. Tal proposição está de acordo com Oliveira (2016b), segundo o qual, a longo prazo, os desembolsos do BNDES têm o papel de aumentar a oferta agregada acima da demanda da economia, criando condições para o crescimento econômico sustentado.

\section{Considerações finais}

Este estudo se propôs a avaliar os impactos do crédito do BNDES em termos de geração de emprego formal em empresas da agroindústria brasileira no período de 2008 a 2010, procurando captar os efeitos das mudanças em termos de liberação de crédito no período pós-política anticíclica, por meio de PSM e DID.

Na estimação do PSM, inicialmente os resultados do Probit apontaram que a probabilidade de as empresas da agroindústria acessarem o crédito do BNDES está vinculada à região onde as empresas estão instaladas, ao grau de instrução dos funcionários, ao porte da empresa e ao PIB per capita do município. Pelo PSM, foi possível também construir um grupo de controle balanceado para comparação contrafactual com base em tais características observáveis.

Após a confirmação do balanceamento da amostra, o método DID foi empregado para comparar os resultados do grupo de tratamento e controle antes e depois da intervenção (política anticíclica). Os resultados do DID apontam que, para a amostra em análise, nas empresas financiadas entre 2009 e 2010, o impacto no crescimento do emprego foi estatisticamente significativo, revelando que as empresas pertencentes à agroindústria que receberam o crédito do BNDES apresentaram dinâmica diferenciada em termos de geração de emprego, em relação às empresas que não receberam financiamento. Os resultados apontam ainda que as empresas que receberam financiamento apresentaram estoque de emprego em 2010, em média, 19,1\% superior ao que teriam se não tivessem recebido o financiamento.

Sendo assim, pode-se concluir que a atuação do BNDES em termos de política anticíclica, no período de 2009 e 2010, foi importante para minimizar os impactos da crise econômica internacional na agroindústria. A ampliação dos desembolsos do banco para financiar investimentos produtivos contribuiu para que empresas agroindustriais pudessem realizar antecipação de investimentos em infraestrutura e realizar investimentos em tecnologia e equipamentos, concorrendo, assim, para a geração de emprego.

Dada a importância da agroindústria para a economia brasileira na geração de emprego e renda para as populações rural e urbana, na geração de divisas via exportação, na participação no PIB e, em especial, por estar presente em todas as regiões do país, as políticas públicas de crédito são essenciais e servem como mecanismos de dinamização das economias locais ao contribuir para a geração de emprego e renda, cooperando para a redução das disparidades regionais e o desenvolvimento regional.

Dessa forma, o estudo contribui para o crescente debate sobre o papel dos programas de crédito público e bancos de desenvolvimento na promoção do desempenho das empresas, bem como em sua atuação em políticas anticíclicas, e instiga novas pesquisas sobre o assunto, em virtude de expandir as análises além dos efeitos médios do tratamento e em nível setorial. Este estudo é um dos primeiros esforços na avaliação de impacto dos desembolsos do BNDES a empresas pertencentes à agroindústria. Sendo assim, sugere-se, para pesquisas futuras, um aprofundamento do tema em questão com investigação das diferenças dos impactos sobre o emprego por setor e localização geográfica, além de ampliação do horizonte temporal para que se possa realizar uma análise da política de desembolso não apenas em período de crise, mas também verificar os impactos desta nos períodos de crescimento da economia. 


\section{REFERÊNCIAS}

Alves, P., Botelho, D., \& Fernandes, J. (2018). Avaliação de impacto dos financiamentos do BNDES sobre as firmas industriais brasileiras no período pós-crise. In J.A. De Negri, B, C. Araújo \& R. Bacette (Orgs.), Financiamento do desenvolvimento no Brasil (p. 316). Brasília: IPEA.

Aoki, V. C. G., \& Badalotti, R. M. (2014). Dificuldades e perspectivas no acesso de micro e pequenas empresas a linhas de crédito públicas: o caso de Chapecó. Revista de Administração PúblicaRAP, 48(5), 1305-1327.

Araújo, V. L., \& Gentil, D. L. (2011). Avanços, recuos, acertos e erros: uma análise da resposta da política econômica brasileira à crise financeira internacional (Textos para discussão, No. 1602, pp. 1-43). Brasília: IPEA

Araújo, V. L., \& Pires, M. (2010). Políticas econômicas para superaçã o da crise no Brasil: a ação anticíclica em debate. In J. C. Cardoso Junior (Coord.), Brasil em desenvolvimento: estado planejamento e políticas públicas (Vol. 1). Brasília: IPEA.

Banco de Desenvolvimento do Extremo Sul - BRDE. (2020). Taxa de Longo Prazo (TLP) vai substituir a TJLP a partir de $1^{\circ}$ de janeiro. Recuperado em 4 de outubro de 2019, de https://www. brde.com.br/noticia/taxa-de-longo-prazo-tlp-vai-substituir-a-tjlp-a-partir-de-1o-de-janeiro/

Banco Nacional de Desenvolvimento Econômico - BNDES. (2015). Informação Setorial. Área de agropecuária e inclusão social, n.2. Recuperado em 20 de dezembro de 2017, de https:// web.bndes.gov.br/.

Banco Nacional de Desenvolvimento Econômico - BNDES. (2017a). Central de downloads. Recuperado em 4 de outubro de 2019, de https://www.bndes.gov.br

Banco Nacional de Desenvolvimento Econômico - BNDES. (2017b). Fontes de recursos. Recuperado em 4 de outubro de 2019, de https://www.bndes.gov.br/wps/portal/site/home/ relacoes-com-investidores/fontes-de-recursos

Banco Nacional de Desenvolvimento Econômico - BNDES. (2020). O Banco do Desenvolvimento do Brasil. Recuperado em 4 de outubro de 2019, de https://www.bndes.gov.br/SiteBNDES/ bndes/bndes_pt/Hotsites/Relatorio_Anual_2014/banco_desenvolvimento.html

Bastos, E. K. (2017). Como será calculada a TLP (que substituirá a TJLP). Carta de Conjuntura, 36(3), 1-6. Recuperado em 4 de outubro de 2019, de https://www.ipea.gov.br/portal/images/ stories/PDFs/conjuntura/170913_cc36_boletim_de_expectativas_set_17.pdf

Beck, T., Demirguç-kunt, A., \& Maksimovic, V. (2005). Financial and legal constraints to growth: does firm size matter? The Journal of Finance, 60(1), 137-177.

Becker, S. O., \& Ichino, A. (2002). Estimation of average treatment effects based on propensity scores. The Stata Journal, 2(4), 358-377.

Bel Filho, E. D., Lima, J. F., Capanema, L. X. L., \& Moraes, V. E. G. (2012). Apoio do BNDES a agroindústria: retrospectiva e visão de futuro. Rio de Janeiro: BNDES.

Brasil. Ministério do Desenvolvimento Agrário - MDA. (2007). Programa de agroindustrialização da produção da agricultura familiar. Edição 2007/2010. Brasília: MDA.

Bruck, N. (1998). The role of development banks in the twenty-first century. Journal of Emerging Markets, 3, 39-67.

Carrer, M. J., Souza Filho, H. M., \& Vinholis, M. M. B. (2013). Determinantes da demanda de crédito rural por pecuaristas de corte no estado de São Paulo. Revista de Economia e Sociologia Rural, 51(3), 455-478. 
Coelho, D., \& De Negri, J. A. (2010). Impacto do financiamento do BNDES sobre a produtividade das empresas: uma aplicação do efeito quantílico de tratamento. In Anais do $38^{\circ}$ Encontro Nacional de Economia - ANPEC. Niterói: ANPEC.

Couto, A. C. L., \& Trintim, J. G. (2012). O papel do BNDES no financiamento da economia brasileira. In Anais do XXI Encontro Nacional de Economia Política (pp. 1-19). São Paulo.

Daniel, L. P. (2016). Avaliação dos impactos sócio-econômicos da política de crédito subsidiado do Fundo Constitucional de Financiamento do Norte (FNO)(Tese de doutorado). Programa de Pós-graduação em Economia Aplicada, Universidade Federal de Viçosa, Viçosa.

De Aghion, B. A. (1999). Development banking. Journal of Development Economics, 58(1), 83-100.

De Negri, J. A., Maffioli, A., Rodrigues, C., \& Vázquez, G. (2011). The impact of public credit programs on Brazilian firms (Working Paper, No. IDB-WP-293). Washington: Inter-American Development Bank.

Departamento Intersindical de Estatística e Estudos Socioeconômicos - DIEESE. (2017). Análise das mudanças na Taxa de Juros de Longo Prazo - TJLP(Nota Técnica, No. 182). Recuperado em 4 de outubro de 2019, de https://www.dieese.org.br/notatecnica/2017/notaTec182TJLP.pdf

Favro, J. (2019). Ensaios sobre a agroindústria no Brasil: Uma análise para o período de 2006 a 2016 (Tese de doutorado). Programa de Pós-graduação em Ciências Econômicas, Universidade Estadual de Maringá, Maringá.

Hermann, J. (2010). Development banks in the financial-liberalization era: the case of BNDES in Brazil. CEPAL Review, 100, 189-203.

Hirt, C. (2013). O papel do BNDES nas políticas de desenvolvimento e integração regional. Espaço e Economia. Revista Brasileira de Geografia Econômica, 2(3). https://doi.org/10.4000/ espacoeconomia.423.

Instituto Brasileiro de Geografia e Estatística - IBGE. (2018). Pesquisa Industrial Anual. Recuperado em 4 de outubro de 2019, de https://sidra.ibge.gov.br/pesquisa/pia-empresa/quadros/

Instituto Brasileiro de Geografia e Estatística - IBGE. (2020). Pesquisa Industrial Anual. Recuperado em 15 de novembro de 2021, de https://sidra.ibge.gov.br/pesquisa/pia-empresa/quadros/

Jesus Júnior, C., Ormond, J. G. P., \& Braga, N. M. (2007). O BNDES e a agroindústria. Informe Setorial - Área Industrial, 1(2), 1-4. Recuperado em 4 de outubro de 2019, de https://web. bndes.gov.br/bib/jspui/bitstream/1408/5328/2/IS_AS\%200\%20BNDES\%20e\%20a\%20 agroindustria_2_P.pdf

Khandker, S. R., Koolwal, G. B., \& Samad, H. A. (2010). Handbook on impact evaluation quantitative methods and practices. Washington: The World Bank.

Kohlhepp, G. (2010). Análise da situação da produção de etanol e biodiesel no Brasil. Estudos Avançados, 24(68), 223-253.

Lechner, M. (2011). The estimation of causal effects by difference-in-difference methods. Foundations and Trends in Econometrics, 4(3), 165-224.

Lee, H., \& Chambers, R. G. (1986). Expenditure constraints and profit maximization in U. S. agriculture. American Journal of Agricultural Economics, 68(4), 857-865.

Lee, M.-J. (2005). Micro-econometrics for policy, program, and treatment effects. New York: Oxford University Press Inc.

Lobo, C. E. (2012). O impacto do BNDES Exim no tempo de permanência das firmas brasileiras no mercado internacional: uma análise a partir dos microdados. Planejamento e Políticas Públicas, 38, 9-36. 
Machado, L., Parreiras, M., \& Peçanha, V. (2011). Avaliação de impacto do uso do Cartão BNDES sobre o emprego nas empresas de menor porte. Revista do BNDES, 18(36), 5-42.

Maffioli, A., de Negri, J. A., Rodrigues, M., \& Vazquez-Bare, G. (2016). Public credit programmes and firm performance in Brazil. Development Policy Review, 35(5), 675-702.

Mora, M. (2015). A evolução do crédito no Brasil entre 2003 e 2010 (Texto para discussão, No. 2022). Brasília, DF: IPEA.

Morais, J. M. (2008). Programas especiais de crédito para micro, pequenas e médias: BNDES, PROGER e fundos constitucionais de financiamento. In Instituto de Pesquisa Econômica Aplicada - IPEA. Políticas de incentivo à inovação tecnológica no Brasil. Brasília: IPEA.

Oliveira, A. S. (2016a). The BNDES countercyclical role in the international economic crisis. Textos de Economia, 19(2), 39-59.

Oliveira, G. R. (2016b). Três ensaios sobre avaliação de políticas públicas para o estado de Goiás (Tese de doutorado). Programa de Pós-graduação em Economia, Universidade de Brasília - Faculdade de Administração, Contabilidade e Economia, Brasília.

Oliveira, G. R., Menezes, R. T., \& Resende, G. M. (2015). Efeito dose resposta do Fundo Constitucional de Financiamento do Centro-Oeste (FCO) no Estado de Goiás (Texto para discussão, No. 2133). Brasília: IPEA.

Paredes, J. R. P. (2016). Avaliação de impacto do Proagro mais: um estudo de caso (Tese de doutorado). Programa de Pós-graduação em Economia Aplicada, Escola Superior de Agricultura "Luiz de Queiroz", Universidade de São Paulo, Piracicaba.

Pereira, R. (2007). Ação do BNDES sobre o emprego formal: efeito nas empresas financiadas. Revista do BNDES, 14(27), 27-42.

Relação Anual de Informações Sociais - RAIS. (2020). Recuperado em 4 de outubro de 2019, de http://trabalho.gov.br/rais

Ribeiro, E., \& De Negri, J. (2009). Public credit use and manufacturing productivity in Brazil. Rio de Janeiro: CADE.

Rosenbaum, P., \& Rubin, D. (1983). The central role of the propensity score in observational studies for causal effects. Biometrika, 70(1), 41-55.

Serviço Brasileiro de Apoio às Micro e Pequenas Empresas - SEBRAE. (2013). Anuário do trabalho na micro e pequena empresa (6th ed., 288 p.). Brasília: DIEESE - Departamento Intersindical De Estatística E Estudos Socioeconômicos.

Schuntzemberger, A. M. S. (2016). Evidências do impacto do cooperativismo de crédito na agropecuária brasileira (Tese de doutorado). Universidade Federal do Paraná, Curitiba.

Schuntzemberger, A. M. S., Jacques, E. R., Oliveira, F. O., \& Sampaio, A. V. (2015). Análises quase-experimentais sobre o impacto das cooperativas de crédito rural solidário. Revista de Economia e Sociologia Rural, 53(3), 498-515.

Shepherd, A. W., Cadilhon, J.-J., \& Galvez, E. (2009). Commodity associations: a tool for supply chain development? Agricultural management, marketing and finance occasional(No. 24). Rome: FAO.

Silva, N. L. C., \& Saccaro, A. (2019). Efeitos do crédito do BNDES na sobrevivência das firmas brasileiras (Texto para discussão, No. 2531). Brasília: IPEA.

Simonassi, A. G., Arraes, R. D. A., \& Silva, J. H. F. (2017). Política de crédito do BNDES e sustentabilidade de crescimento do setor primário. Revista de Economia e Sociologia Rural, 55(1), 31-46. 
Soares, R. B., Sousa, J. M. P., \& Pereira Neto, A. P. (2009). Avaliação de impactos do Fundo Constitucional de Financiamento do Nordeste (FNE): emprego, massa salarial e salário médio (Série Avaliação de Programas e Projetos). Fortaleza: Banco do Nordeste do Brasil.

Soares, R. B., Vaiana, L. F. G., Gonçalves, M. F., \& Souza, J. M. G. (2013). Avaliação de impacto e eficiência das empresas beneficiadas pelo Fundo Constitucional de Financiamento do Nordeste (FNE) na geração de emprego, massa salarial e salário médio 2000-2008. Fortaleza: BNB.

Soares, R. B., Viana, L. F. G., Gonçalves, M. F., \& Souza, J. M. G. (2014). Avaliação de impacto e eficiência das empresas beneficiadas pelo Fundo Constitucional de Financiamento do Nordeste (FNE) na geração de emprego, massa salarial e salário médio 2000-2008. (Série Avaliação de Programas e Projetos). Fortaleza: Banco do Nordeste do Brasil.

Sousa, F. L., \& Ottaviano, G. I. P. (2018). Aliviando as restrições de crédito em países emergentes: o impacto dos financiamentos do BNDES na produtividade das firmas industriais brasileiras. São Paulo: IEDI. Recuperado em 4 de outubro de 2019, de https://web.bndes.gov.br/bib

Todaro, M. P., \& Smith, S. C. (2012). Economic development (11. ed.). Boston: Pearson.

Wegelin, M.J. C. (2014). O impacto da política de crédito do BNDES no desenvolvimento econômico e social dos municípios brasileiros (Dissertação de mestrado). Rio de Janeiro: IBMEC.

Wooldridge, J. M. (2002). Econometric analysis of cross section and panel data. Cambridge, MA: MIT Press.

Yeyati, E. L., Micco, A., \& Panizza, U. (2004). Should the government be in the banking business? The role of state-owned and development banks (Working Paper, No. 517). Washington: Inter-American Development Bank.

Zica, R. M. F., \& Martins, H. C. (2008). Sistema de garantia de crédito para micro e pequenas empresas no Brasil: proposta de um modelo. Revista de Administração Pública, 42(1), 181-204. 